\title{
INVITRO ANALYSIS OF TIME-KILL CURVES OF SOME ANTIMICROBIAL AGENTS AGAINST SALMONELLA TYPHI
}

\author{
Aliyu A.S. ${ }^{1}$, Ahmed I. ${ }^{1}$, Abdulmalik I. ${ }^{2}$, Shamsiyya M.S. ${ }^{2}$, \\ Usman Y.S. ${ }^{3}$, Sadisu F.U. ${ }^{1}$ and Haruna M. ${ }^{4}$ \\ ${ }^{1}$ Department of Microbiology, Kano University of Science and Technology, Wudil. \\ ${ }^{2}$ Medical Education Unit, College of Medicine, Kaduna State University. \\ ${ }^{3}$ Department of Microbiology, Federal University Dutsinma, Katisna State. \\ ${ }^{4}$ Department of Biology, Kano University of Science and Technology, Wudil.
}

Corresponding Author Email: aliyujanzaki@gmail.com

Cite this article:

Aliyu A.S., Ahmed I., Abdulmalik I., Shamsiyya M.S., Usman Y.S., Sadisu F.U., Haruna M. (2021), Invitro Analysis of Time-Kill Curves of Some Antimicrobial Agents Against Salmonella Typhi. African Journal of Biology and Medical Research 4(3), 108-118. DOI: 10.52589/AJBMRITLIZNET.

\section{Manuscript History}

Received: 2 June 2021

Accepted: 12 Aug 2021

Published: 31 Aug 2021

Copyright $\odot 2020$ The Author(s).

This is an Open Access article distributed under the terms of Creative Commons AttributionNonCommercial-NoDerivatives 4.0 International (CC BY-NC-ND

4.0 ), which permits anyone to share, use, reproduce and redistribute in any medium, provided the original author and source are credited.
ABSTRACT: Due to the high prevalence of typhoid fever and the periodic nature of Salmonella infections despite the various antimicrobial agents used to treat these infections, the need to open up new strategies for antimicrobial susceptibility rather than the MIC alone arises. This study determines the time-kill curves using four different antimicrobial agents: Gentamicin, Ceftriaxone, Cloxacillin, and Ofloxacin at different concentrations of $1 x, 2 x$, and $4 x$ of their respective MICs. The finding of this study reveals that at $1 x M I C$, all the antimicrobial agents used, except for Gentamicin, show non-bactericidal activity against the isolates after eight hours of exposure. This study suggests that analyzing the time-kill curves in typhoid fever treatment will help determine the appropriate dose to treat the infection.

KEYWORDS: Antimicrobial, Time-kill Curves, Salmonella Typhi. 


\section{INTRODUCTION}

Over the past decade, several strains (types) of Salmonella typhi have become resistant to multiple antibiotics. The percent of Salmonella typhi infections non susceptible to ciprofloxacin reached $74 \%$ in 2017 , severely limiting treatment options. Salmonella typhi causes an estimated 5,700 infections and 620 hospitalizations each year in the United States. Worldwide, an estimated 11 to 21 million infections occur each year. Typhoid fever requires treatment with antibiotics, which is complicated by increasing resistance (CDC, 2016).

The relatively long incubation period of typhoid fever suggests that $S$. typhi can evade or suppress detection by the innate immune system during the initial stages of infection (Crump et al., 2004). Typhoid fever is a systemic febrile illness that requires prompt antibiotic treatment. Worldwide, approximately 12-27 million cases of typhoid fever occur annually (Mogasale et al., 2004). In the United States, approximately 350 culture-confirmed cases are reported to CDC each year. Most U.S. patients report having traveled internationally within the preceding 30 days. Over the past several decades, the emergence of Typhi that is multidrug-resistant (MDR) to historically used first-line antibiotics, such as Chloramphenicol, Ampicillin, and Trimethoprim-sulfamethoxazole, led to the use of fluoroquinolones (e.g. Ciprofloxacin) as the first-line treatment (Crump et al., 2015). However, since the early 2000s, increasing fluoroquinolone non-susceptibility (intermediate or full resistance to Ciprofloxacin), especially in South Asia, has led to the use of third-generation cephalosporins (e.g. ceftriaxone) as a recommended first-line treatment.

Antimicrobial resistance (AMR) is an increasing threat to global health. There are $>14$ million cases of enteric fever every year and > 135,000 deaths (Eibacha et al., 2016). Unfortunately, AMR is widespread, and patients treated with ineffective antimicrobials show a poor clinical response and a higher rate of complications and deaths, as well as prolonged fecal shedding, which sustains transmission and induces secondary cases (Arndt et al., 2014). Hence, this study focused on in vitro analysis of time-kill curves of some antimicrobial agents against Salmonella typhi.

\section{MATERIALS AND METHODS}

\section{Preparation of Inoculum}

Isolates of Salmonella typhi were isolated from patients attending the laboratory unit of Wudil General Hospital, Kano, Nigeria. These were clinical isolates from the stools of patients who were attending the hospital. Isolates were further confirmed following standard laboratory procedures as described by theAmerican Public Health Association (2018).

\section{Determination of Bacterial Growth Curve}

Growth curves of the isolates of Salmonella typhi were determined by modifying the method described by Shrivastava et al. (2017) and Foerster et al. (2015) using spectrophotometry. In this method, the spectrophotometer (Spectrophotometer 20D Techmel \& Techmel USA) was power on, allowed to warm up for ten (10) minutes and set up to a wavelength of OD600nm. $5 \mathrm{~mL}$ of uninoculated sterile nutrients broth media were pipetted into a clean cuvette and the machine was blanked by setting it to 0 ABS with this sample. Two to three colonies of a $20 \mathrm{~h}$ 
grown on SSA of the organism studied were suspended in $50 \mathrm{~mL}$ prewarmed $\left(37^{\circ} \mathrm{C}\right)$ nutrients broth gently shaken to ensure homogenization. Immediately after inoculating, a $5 \mathrm{~mL}$ sample of the inoculated media was pipetted into a clean cuvette and placed in the blanked spectrophotometer, and the OD reading was recorded. This reading was recorded at the time " 0 " and repeated at 60 minute intervals until the absorbance no longer increased. The procedure was performed in duplicate and the readings were plotted on a graph with Time on the $\mathrm{X}$-axis and OD on the Y-axis. Only lag, log, and stationary phases were included in the analysis, and the decline phase was excluded.

\section{Preparation of Antibiotics Stock Solutions}

A stock solution of the four antibiotics used based on their activity against the isolates (Gentamicin, Ceftriaxone, Cloxacillin, and Ofloxacin) were prepared as follows: $10 \mathrm{mg}$ of intravenous gentamicin and ceftriaxone solutions per $\mathrm{ml}$ was dissolved in sterile distilled water to a concentration of $25 \mathrm{mg} / \mathrm{ml}$ while Cloxacillin and Ofloxacin were dissolved in $50 \%$ ethanol to a concentration of $25 \mathrm{mg} / \mathrm{ml}$. Appropriate dilutions of the stock solutions were made in Mueller Hinton broth immediately before use.

\section{Determination of Minimum Inhibitory Concentration}

Macrobroth dilution techniques were employed in determining the MIC of the different antibiotics used against the isolates, as described by Burkhard et al., (2004). Different concentrations $(0.125,0.25,0.50$, and 1.0$) \mathrm{mg} / \mathrm{L}$ of antibiotics were differently prepared by serial dilutions in the Mueller Hinton broth medium. Each tube was then inoculated with $1 \mathrm{ml}$, an equivalent of $0.5 \mathrm{McF}$ arland standard turbidity of each of the adjusted bacterial strains. Two blank Mueller Hinton broth tubes, with and without bacterial inoculation, were used as the growth and sterility controls. The bacteria-containing tubes incorporated with the antibiotics were incubated aerobically at $37^{\circ} \mathrm{C}$ for $24 \mathrm{~h}$. After the incubation period, the tubes were observed for the MICs by checking the concentration of the first tube in the series (ascending antibiotic concentrations) that showed no visible trace of growth. The first tube in the series with no visible growth after the incubation period was taken as the MIC.

\section{Determination of Time-Kill Assay}

Time-kill curve analyses were performed through the modification of the method described by Tsuji et al. (2008) and Appiah et al. (2017). Concentrations equal to MIC, twice the MIC, and four times the MIC of the antibiotics were prepared with sterilized Mueller Hinton agar. An inoculum size of $1.0 \times 105 \mathrm{CFU} / \mathrm{mL}$ (CFU was achieved by diluting $0.5 \mathrm{McFarland}$ inoculum into 1000 volumes of distilled water) was added and incubated at $37^{\circ} \mathrm{C}$. The antimicrobials examined were Gentamicin (Pharmax India, Pvt. Ltd), Ceftriaxone (Shanxi Zhongbao Shuguang Pharmaceutical Co. Ltd., China), Ofloxacin (Impulse Pharma Pvt. Ltd., India), and Cloxacillin (Sigma Aldrich, China). Aliquots of $1.0 \mathrm{~mL}$ of the medium were taken at time intervals of $0,2,4,6$, and $8 \mathrm{~h}$ inoculated aseptically into $20 \mathrm{~mL}$ nutrients agar and incubated at $37^{\circ} \mathrm{C}$ for $24 \mathrm{~h}$. A control test was performed for the organisms without the reference antibiotic. The colony forming unit (CFU) of the organisms was determined after the incubation. Antimicrobials were considered bactericidal when a $\geq 3 \log 10$ decrease in CFU/mL was reached compared with the initial inocula. The procedure was performed in duplicate and a graph of the $\mathrm{CFU} / \mathrm{mL}$ was plotted against time. 


\section{RESULTS}

The bacterial quantified growth curve of $S$. Typhi shown in figure 1 revealed that the isolates reach their plateau at $16 \mathrm{~h}$ of incubation while $S$. aureus attained its plateau at $15 \mathrm{~h}$ of incubation. This confirmed the binary multifiable growth of the isolates in the absence of antimicrobials.

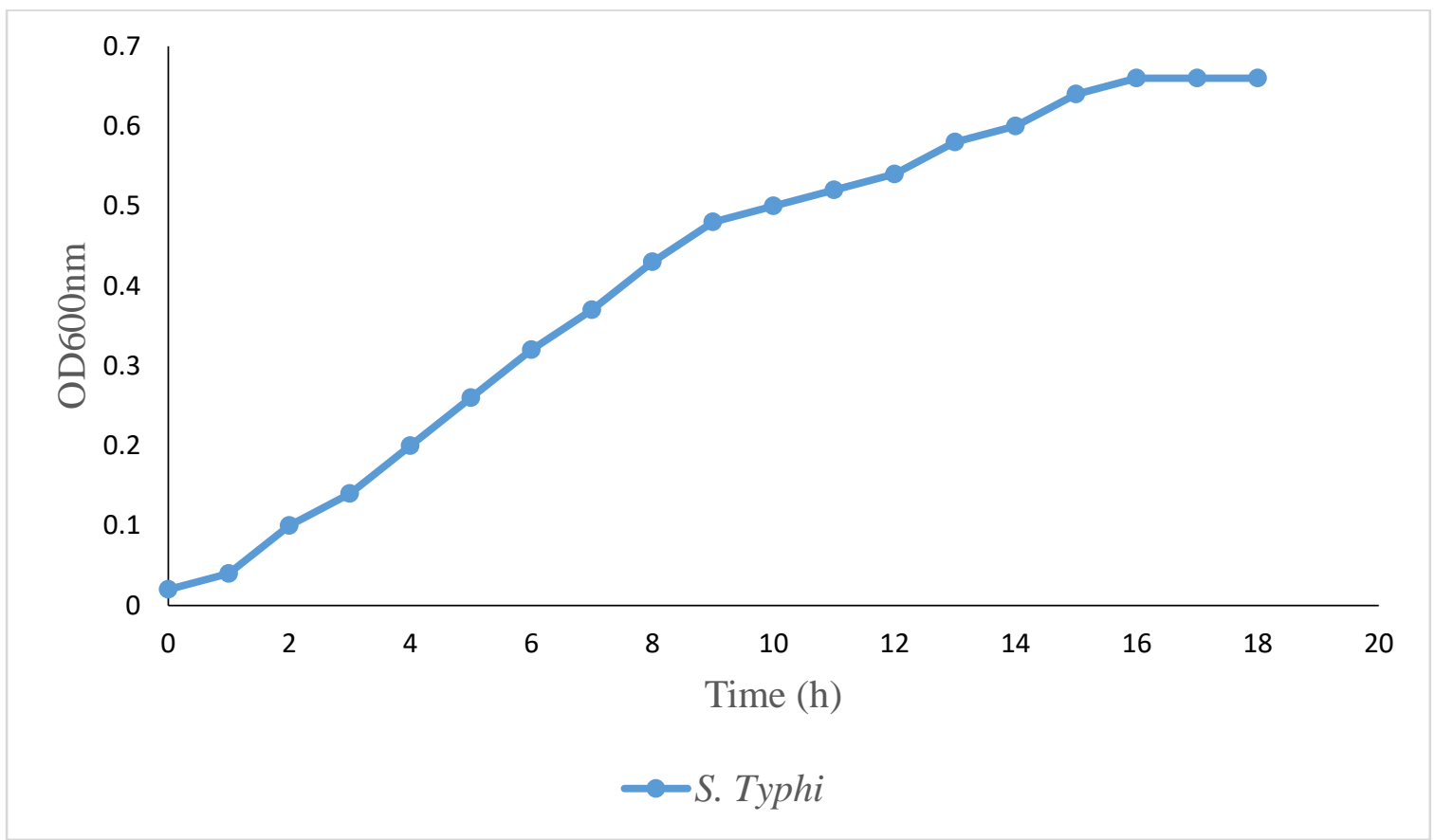

Fig. 1: Quantification of Bacterial Growth Curve Using Spectrophotometer

Table 1 shows the minimum inhibitory concentrations of the Gentamicin, Ceftriaxone, Cloxacillin, and Ofloxacin antibiotics against S. Typhi. The MIC of Gentamicin against the isolates was found to be $0.250 \mathrm{mg} / \mathrm{ml}$, Ceftriaxone has an MIC of $0.125 \mathrm{mg} / \mathrm{ml}$, Cloxacillin has an MIC of > 1, and lastly, Ofloxacin has an MIC of $0.250 \mathrm{mg} / \mathrm{ml}$.

Table 1: Minimum Inhibitory Concentration of Antibiotics Use against the Isolates

\begin{tabular}{ll}
\hline Antibiotics & Salmonella Typhi \\
\hline Gentamicin & $0.250(\mathrm{mg} / \mathrm{ml})$ \\
Ceftriaxone & $0.125(\mathrm{mg} / \mathrm{ml})$ \\
Cloxacillin & $>1(\mathrm{mg} / \mathrm{ml})$ \\
Ofloxacin & $0.250(\mathrm{mg} / \mathrm{ml})$ \\
\hline
\end{tabular}


All the antimicrobial agents used show a non-bactericidal effect against $S$. Typhi except for Gentamicin at $1 \mathrm{x}$ the MIC. Also, in all four cases, the bactericidal effect increases with the duration of exposure.

Time-kill curves for four antimicrobials were made (Gentamicin, Ceftriaxone, Cloxacillin, and Ofloxacin) against the isolates (Fig. 2). Similar to the effect of Gentamicin (Fig. 2a), Ceftriaxone (Fig. 2b) exhibited rapid killing during the first two hours of the assay for concentrations above the MIC. Cloxacillin (Fig. 2c) and Ofloxacin (Fig. 2d) showed little effect from 0 hours to 4 hours; however, after that, the growth rate decreased rapidly. Bactericidal effects were considered by reduction greater than $3 \log 10$ in colony-forming units per milliliters compared to the initial inocula.

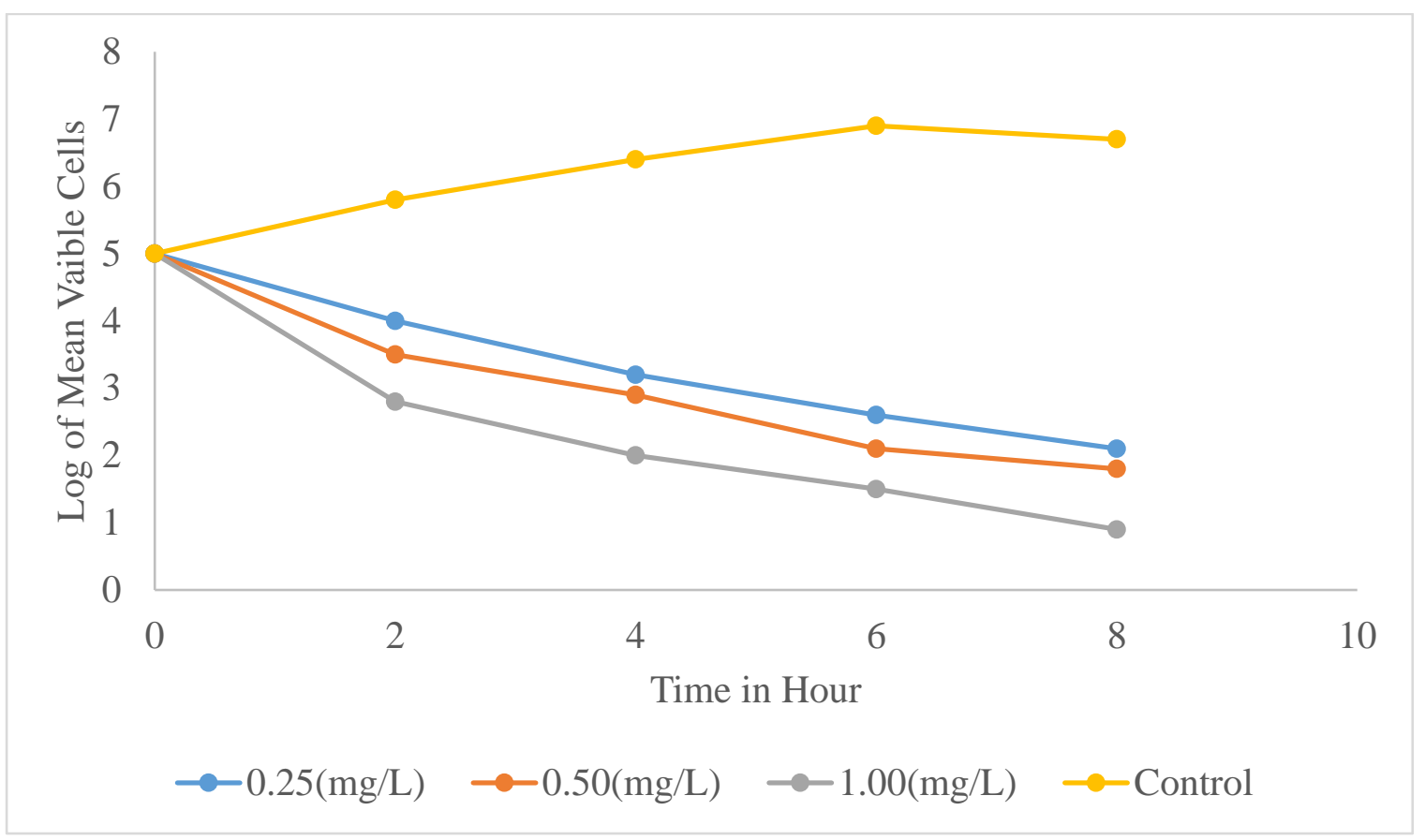

Fig. 2a: Time kill kinetics of Gentamicin antibiotic against Salmonella Typhi; means compared to control showed a significant statistical difference using one way ANOVA at $\mathbf{p}<0.05$ 
African Journal of Biology and Medical Research

ISSN: $2689-534 \mathrm{X}$

Volume 4, Issue 3, 2021 (pp. 108-118)

www.abjournals.org

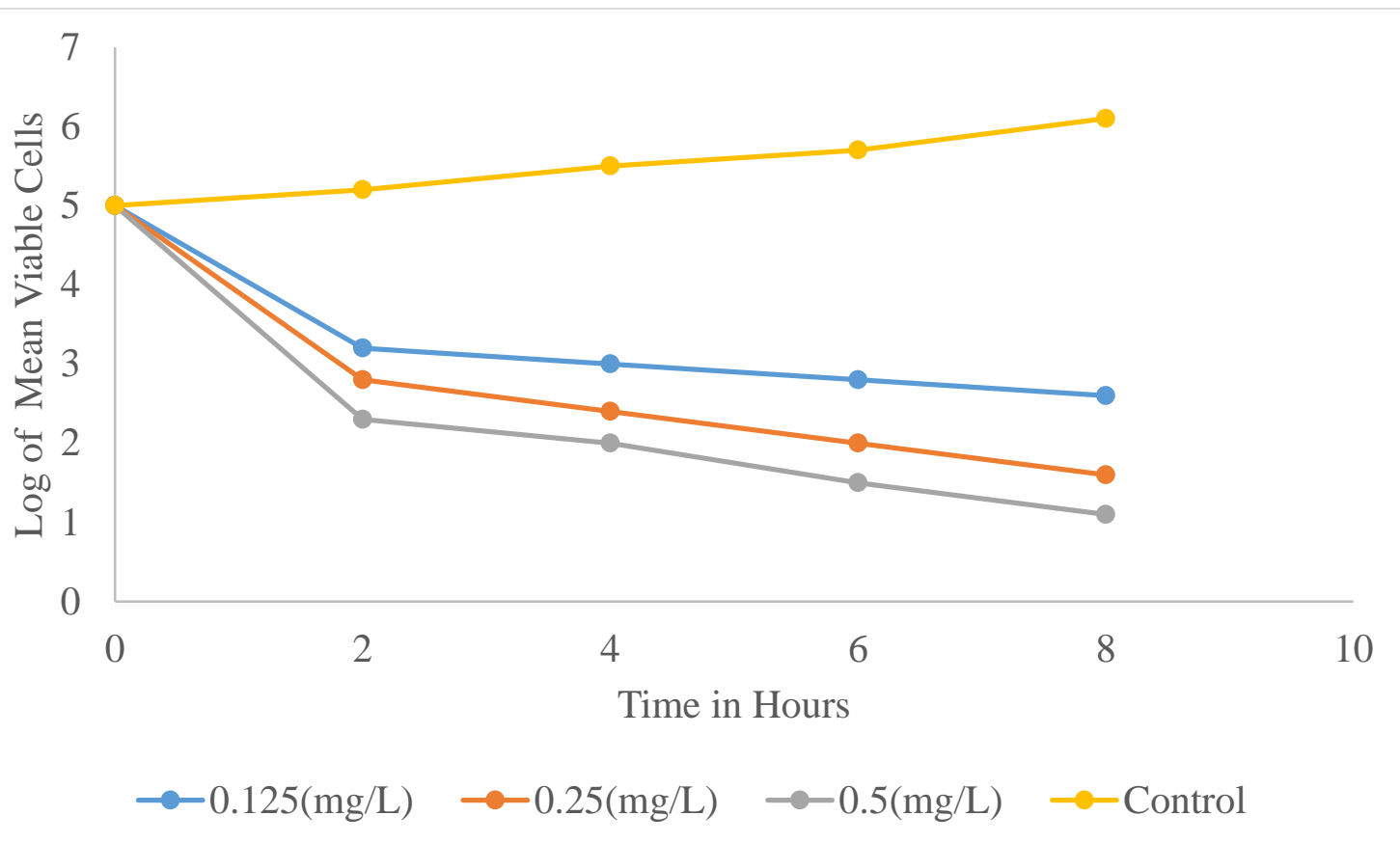

Fig. 2b: Time kill kinetics of Ceftriaxone antibiotic against Salmonella typhi; means compared to control showed a significant statistical difference using one way ANOVA at $\mathbf{p}<0.05$

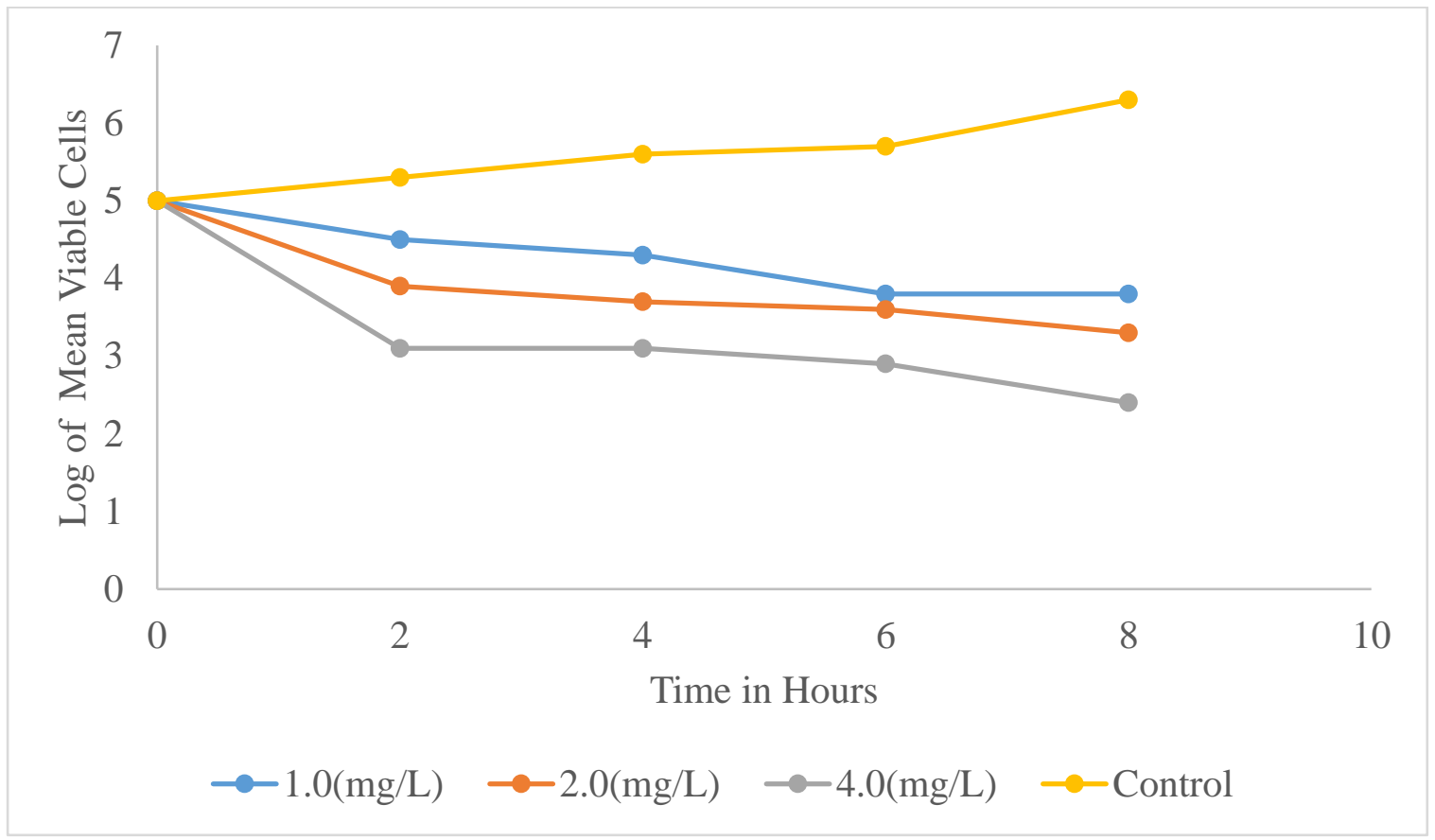

Fig. 2c: Time kill kinetics of Cloxacillin antibiotic against Salmonella typhi; means compared to control showed a significant statistical difference using one way ANOVA at $\mathbf{p}<0.05$ 


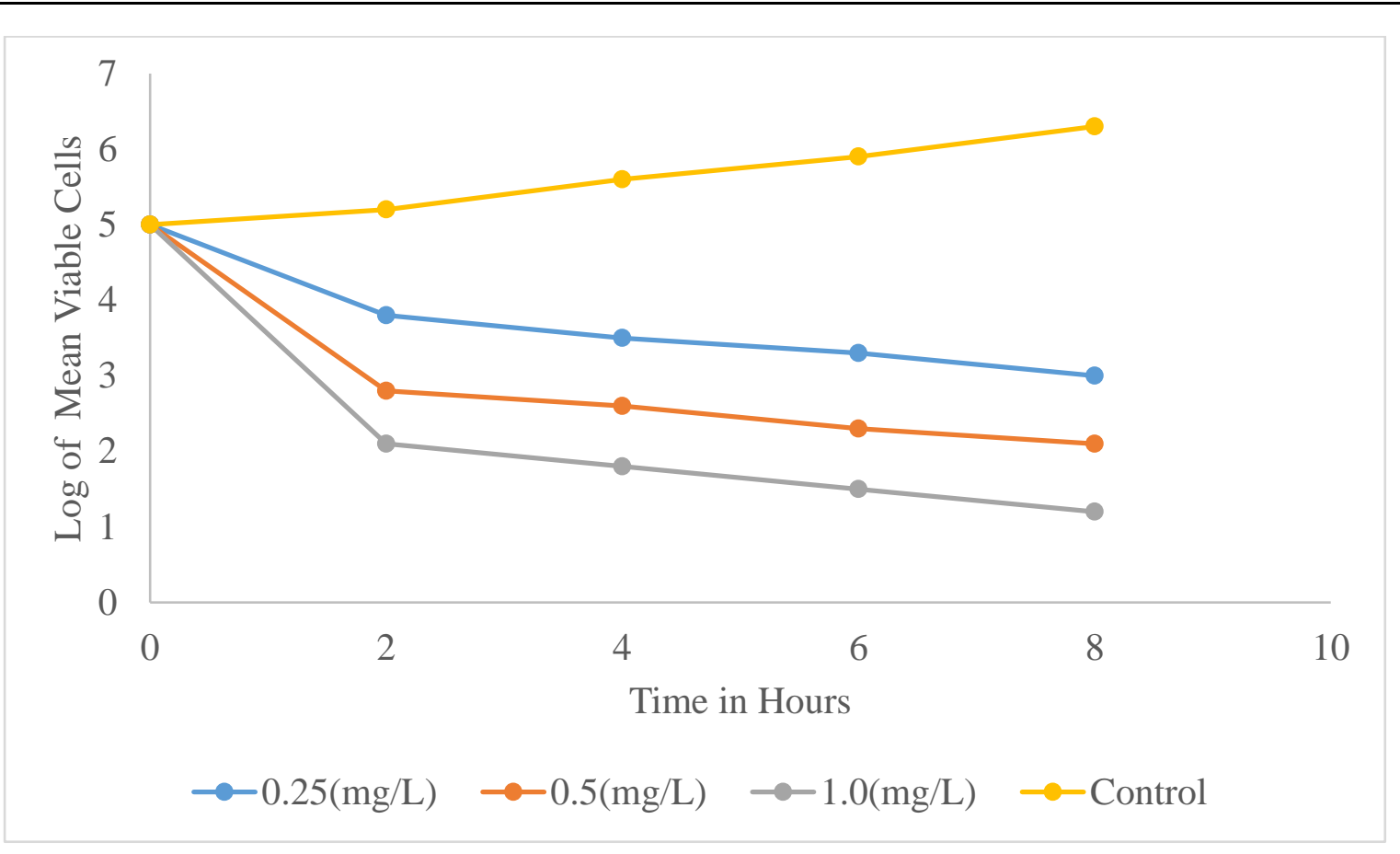

Fig. 2d: Time kill kinetics of Ofloxacin antibiotic against Salmonella typhi; means compared to control showed a significant statistical difference using one way ANOVA at $\mathbf{p}<0.05$

\section{DISCUSSION}

In this study, a standardized in vitro time-kill curve assay was developed and the resulting data were used to suggest the appropriate method in the evaluation of antimicrobial treatment options in vitro, as one of the tools that are urgently needed to support tackling the problem of antimicrobial-resistant S. typhi (Ao et al., 2010).

The established time-kill assay will function well with different chemotherapeutic agents, including highly effective ones. The assay time was limited to eight hours and growth in the absence of antimicrobials was highly consistent and exponential for the strain. The analysis of time-kill data confirmed the robust bactericidal effects of gentamicin and ceftriaxone.

Gentamicin is a member of aminoglycoside antibiotics with a broad-spectrum activity against Gram-negative and Gram-positive bacteria in combination with other antibiotics. The effective bactericidal activity shown against $S$. typhi is within the expectation in vitro but because Gentamicin and other aminoglycosides have difficulty penetrating tissues or cells, they are less likely to be effective for facultative intracellular pathogens like $S$. typhi (Mogasale et al., 2014). However, when dealing with multi-drug resistance S. typhi and other likable critical situations, gentamicin can be suggested for a prescription (Chen et al., 2013).

According to NCCLS MIC cut-offs for most of the Enterobacteriaceae, the MIC of Gentamicin was found to be $\leq 1 \mathrm{mg} / \mathrm{ml}$. This conformed with our finding that the MIC of the strain of $S$. typhi used is $0.250 \mathrm{mg} / \mathrm{ml}$ and it does not exceed the antibiotic breakpoint. In addition, this 
current study found that Gentamicin showed a bactericidal effect on the tested $S$. typhi isolates at very low concentrations $(0.250 \mathrm{mg} / \mathrm{mL})$ throughout the established time-kill curves.

Ceftriaxone is a third-generation cephalosporin that is widely used in the treatment of invasive Salmonella infections (Kariuki et al., 2015). A lot of studies reported the Salmonella resistance to a variety of cephalosporin antibiotics including Ceftriaxone; this resistance to ceftriaxone serves as an alarming challenge in the treatment of Salmonella infections as reported by Salmon-Rousseau et al. (2016). Salmonella typhi is one of the serovars of Salmonella that are spread worldwide and are associated with resistance in both humans and animals (Arlet et al., 2006; Eng et al., 2015). However, the particular strain isolated in this study shows a high degree of susceptibility to Ceftriaxone; this indicates that the gene responsible for Ceftriaxone resistance is absent or inactive.

Ofloxacin is also an extensive spectrum of fluoroquinolone antibiotics; several studies report the weakened activity of Ofloxacin against Salmonella, indicating an acquired gene for Ofloxacin resistance (Kariuki et al., 2015). Chau et al. (2007) reported a reduced susceptibility to fluoroquinolones that is predominantly associated with point mutations in gyrA. However, the strain used in this study was found to be susceptible to Ofloxacin, indicating a non-mutation in gyrA.

Moreover, results obtained on exposing this strain of $S$. typhi show significant less activity. This is no surprise since Cloxacillin is a second-generation penicillin with a narrow spectrum, which works by inhibiting the cell wall synthesis of most bacteria. This nature of the activity is more peculiar to inhibiting the growth of Gram-positive bacteria (Reis et al., 2011).

Although, results obtained in vitro do not always conform to in vivo effect but of course, we assumed a replica; therefore, the use of Ceftriaxone, Ofloxacin, and Gentamicin in the treatment of typhoid fever needs a critical clinical consideration before operation to avoid the misuse and overuse of antimicrobial agents, and accelerate the development of new treatment options against salmonellosis.

Over the past decade, several strains (types) of Salmonella typhi have become resistant to multiple antibiotics. One recently emerging strain of extensively drug-resistant (XDR) Salmonella typhi is resistant to all but two antibiotic classes recommended for treatment (macrolides and carbapenems). Since 2016, an ongoing outbreak of XDR typhoid fever has sickened more than thousands of people in Nigeria.

Nigeria Center for Disease Control and other health agencies are working with public health partners across the globe, including Primary Health Care Management Boards, to strengthen prevention efforts, including vaccination.

As $S$. typhi continues to be prevalent, with an estimated incidence of 33 million infections each year in the developing countries of Africa, like Nigeria, the South African republic, and other sub-Saharan countries, an efficient antibiotic is necessary for individuals with typhoid fever. Ideally, therapy should begin after clinical diagnosis has been made, and no antimicrobial sensitivity testing reports should be used.

Therefore, the growth of antibiotic resistance in epidemic strains in poor countries-like Chloramphenicol, Ampicillin, and Trimethoprim is of great concern. Ampicillin and Trimethoprim have been coded with plasmids of about $100 \mathrm{MDa}$ of the H1 incompatibility 
group (inc H1) in all multiresistant bacteria that are resistant to Chloramphenicol (Rowe et al., 1997).

In Tajikistan, there was a large epidemic of multiresistant strains spreading through polluted water in 1997 (Murdoch et al., 1998), and contaminated ice cream in the Philippines in the early 1990s was affected by a big multiresistant S. typhi outbreak (Superable et al., 1994). More than 6000 cases were documented in the waterborne outbreak of Tajikistan and the emergence of reduced Ciprofloxacin susceptibility was alarming (Threlfall et al., 2001).

In many cases, Ciprofloxacin-resistant bacteria (MIC: $512 \mathrm{mg}-1$ ) was also resistant to nalidixic acid. Moreover, Cloxacillin, Ampicillin, and Trimethoprim were also significantly reduced to over $50 \%$ of the isolates with decreased sensitivity to Ciprofloxacin. Several individuals with reduced Ciprofloxacin susceptibility did not react to fluoroquinolone antimicrobial therapy. Ceftriaxone was the alternate antibiotic most often utilized in these cases (Threlfall, 2000).

\section{CONCLUSION}

The establishment of a time-kill curve assay could be used for in vitro evaluation of new and existing antimicrobials agents against Salmonella typhi and other strains of bacteria as a new strategy to fight antimicrobial drugs resistance.

The method of time-kill curves explored in this study are more standardized in evaluating the activity of antimicrobial agents against $S$. typhi; hence, more strains of $S$. typhi have to be screened with a variety of antimicrobial agents using this method in our clinical settings.

\section{REFERENCES}

Ao TT, Feasey NA, Gordon MA, Keddy KH, Angulo FJ, Crump JA. 2015. Global burden of invasive nontyphoidal Salmonella disease, 2010(1). Emerg Infect Dis. 21(6):941-949.

Appiah, T., Yaw D. B., and Christian, A. (2017). Antimicrobial Activities and Time-Kill Kinetics of Extracts of Selected Ghanaian Mushrooms. Hindawi Evidence-Based Complementary and Alternative Medicine Volume 2017, Article ID 4534350. https://doi.org/10.1155/2017/4534350

Arlet G, Barrett TJ, Butaye P, Cloeckaert A, Mulvey MR, White DG. 2006. Salmonella resistant to extended-spectrum cephalosporins: prevalence and epidemiology. Microbes Infect. 8(7):1945-1954.

Arndt MB, Mosites EM, Tian M, Forouzanfar MH, Mokhdad AH, Meller M, et al. Estimating the burden of Paratyphoid A in Asia and Africa. PLoS Negl Trop Dis. 2014;8(6):e2925.

Burkhard, M. Iqbal, A. Khatoon, N., Iqbal, N. Naeem, S. and Qureshi, G.A. (2004). Laboratory study of susceptibility of methicillin-resistant Staphylococcus aureus. Pakistan J. Med. Sci. 20: 229-223. 
CDC. National antimicrobial resistance monitoring system for enteric bacteria (NARMS) annual reports and interactive data. Atlanta, GA: US Department of Health and Human Services, CDC; 2016.

Chatham-Stephens K, Medalla F, Hughes M, et al. Emergence of Extensively Drug-Resistant Salmonella Typhi Infections Among Travelers to or from Pakistan - United States, 2016-2018. MMWR Morb Mortal Wkly Rep 2019.

Chau TT, Campbell JI, Galindo CM, Van Minh Hoang N, Diep TS, et al. (2007) Antimicrobial drug resistance of Salmonella enterica serovar typhi in Asia and molecular mechanism of reduced susceptibility to the fluoroquinolones. Antimicrob Agents Chemother 51: 4315-4323.

Chen HM, Wang Y, Su LH, Chiu CH. 2013. Nontyphoid salmonella infection: microbiology, clinical features, and antimicrobial therapy. Pediatr Neonatol. 54(3):147-152.

Crump JA, Sjölund-Karlsson M, Gordon MA, Parry CM. Epidemiology, clinical presentation, laboratory diagnosis, antimicrobial resistance, and antimicrobial management of invasive Salmonella infections. Clin Microbiol Rev 2015;28:901-37.

Crump, J. A., S. P. Luby, and E. D. Mintz. 2004. The global burden of typhoid fever. Bull. World Health Organ. 82:346-353.

Eibacha D, Al-Emrana HM, Dekker DM, Krumkamp R, Yaw A-S, Espinoza LMC, et al. The emergence of reduced ciprofloxacin susceptibility in Salmonella enterica causing bloodstream infections in rural Ghana. Clin Infect Dis. 2016;62(Suppl. 1):S32-S6.

Eng S-K, Pusparajah P, Ab Mutalib N-S, Ser H-L, Chan KG, Lee L-H. 2015. Salmonella: A review on pathogenesis, epidemiology and antibiotic resistance. Front Life Sci. 8(3):284-293.

Kariuki S, Okoro C, Kiiru J, Njoroge S, Omuse G, Langridge G, Kingsley RA, Dougan G, Revathi G. 2015. Ceftriaxoneresistant Salmonella enterica serotype typhimurium sequence type 313 from Kenyan patients is associated with the blaCTX-M-15 gene on a novel IncHI2 plasmid. Antimicrob Agents Chemother. 59(6):3133-3139.

Mandal, S., M.D. Mandal and N.K. Pal. Eastern Mediterranean Health Journal | Past issues | Volume 15, 2009 Volume 15, issue 2 In vitro activity of gentamicin and amikacin against Salmonella enterica serovar Typhi: a search for a treatment regimen for typhoid fever

Mogasale V, Maskery B, Ochiai RL, et al. Burden of typhoid fever in low-income and middle-income countries: a systematic, literature-based update with risk-factor adjustment. Lancet Glob Health 2014;2:e570-80.

Murdoch, D.A., Banatvala, N., Bone, A., Shoismatulloev, B.I., Ward, L.R., Threlfall, E.J. (1998). Epidemic ciprofloxacin-resistant Salmonella Typhi in Tajikistan, Lancet. 351. 339

Reis EMF, Rodrigues DP, Almeida ACF, Hofer E. Prevalence of R-type ACSSuT in strains of Salmonella serovar Typhimurium DT193 isolated from human infections in Brazil. Pan American Journal of Public Health 2011;29:387-392.

Rowe B. Ward L.R. Threlfall E.J. (1997) Multiresistant Salmonella typhi- a world-wide epidemic. Clin. Infect. Dis. 24 (Suppl. 1), S106-S109.

Salmon-Rousseau A, Piednoir E, Cattoir V, de La Blanchardière A. 2016. Hajj-associated infections. Med Maladies Infect.46 (7):346-354. 
Superable, J.F.T., Castillo, M.T.G. and Magboo, F.P. (1994) Multiresistant Salmonella typhi outbreak in Metro Manilla, Philippines. In: Proceedings of the 2nd Asia Pacific Symposium on Typhoid Fever and other Salmonellosis, p.76. Infectious Disease Association of Thailand, Bangkok.

Threlfall E.J. (2000) Multiresistant Salmonella typhimurium DT 104: a truly international multiresistant clone. J. Antimicrob. Chemother. 46, 7-10.

Threlfall E.J. Skinner J.A. Ward L.R. (2001) Detection of decreased susceptibility to ciprofloxacin in Salmonella enterica serotypes Typhi and Paratyphi A. J. Antimicrob. Chemother.48, 740-741.

Tsuji, B. T., Yang, J. C., Forrest, A., Kelchlin, P. A. and Smith, P. F. (2008). "In vitro pharmacodynamics of novel rifamycin ABI-0043 against Staphylococcus aureus," Journal of Antimicrobial Chemotherapy, Vol. 62,no.1,pp.156-160,. 